\section{Jornal Pessoal: o metajornalismo cidadão}

Por Célia Trindade Amorim

Jornalista, doutora em Comunicação e Semiótica pela Pontifícia Universidade Católica de São Paulo (silvamor@ig.com.br)

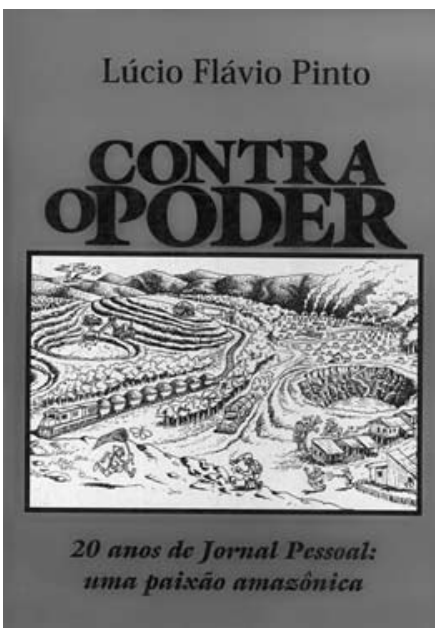

PINTO, Lúcio Flávio. Contra o poder - 20 anos de Jornal Pessoal: Uma paixão amazônica. Belém: Edição do Autor, 2007. 288p

No seu último livro, "Contra o Poder", o sociólogo e jornalista paraense Lúcio Flávio Pinto aborda o complexo cenário político da Amazônia por meio de um conjunto significativo de reportagens extraído dos dois primeiros anos de existência do seu "Jornal Pessoal", uma das mais radicais e longevas publicações alternativas da história do jornalismo brasileiro. Por mídia radical alternativa, entende-se "aquela mídia - em geral de pequena escala e sob muitas formas diferentes - que expressa uma visão alternativa às políticas, prioridades e perspectivas hegemônicas" (Downing, 2002, p. 21).

Apesar do livro não obedecer ao padrão das normas técnicas da academia, a escritura jornalística de Lúcio Flávio Pinto se assenta na investigação rigorosa dos fatos. Para tanto, o autor lança mão de forma explícita do metajornalismo, uma reflexão crítica sobre o próprio jornalismo. Aliás, a crítica "é o método por excelência do fazer jornalismo de Lúcio Flávio Pinto" (Amorim, 2008, p. 169), que tem como fio condutor princípios éticos de uma imprensa voltada efetivamente para o social.
O primeiro capítulo começa com uma indagação: "Por que um Jornal Pessoal?" O autor, que tem 12 livros publicados sobre a região, busca com esse texto responder as razões que o levaram a produzir um jornal eminentemente pessoal. Segundo Lúcio Flávio (Pinto, 2007, p. 8), "se o JP não existisse [...] notícias relevantes [...] deixariam de adquirir a forma impressa" na Amazônia. $\bigcirc$ modelo alternativo seguido foi o do jornalista americano Izzy Feinstein Stone, que editou sozinho o semanário "I. F. Stone's Weekly" por 19 anos, nos Estados Unidos, entre 1952 e 1971.

Ainda neste capítulo, Lúcio Flávio Pinto enfatiza que o objetivo da presente edição, lançada no final de 2007 em meio às comemorações de 20 anos do alternativo, foi "tentar perenizar o 'Jornal Pessoal'” (Pinto, 2007, p. 8), agora com 21 anos de existência, idade rara para jornais desse porte, que, em sua maioria, têm vida efêmera.

"Qual a razão de tão extensa perenidade?", questiona o jornalista (Pinto, 2007, p. 8), que parece mandar um recado para seus adversários, a maioria ligada à elite nortista brasileira, que faz críticas a Lúcio Flávio Pinto por manter o periódico mais por vaidade e capricho do que propriamente por dever profissional. Decerto não é por vaidade. Associar o "Jornal Pessoal" a mero capricho do jornalista, além de ser uma visão simplista do fenômeno alternativo, é querer escamotear uma voz que luta em defesa da causa pública na Amazônia. Talvez esteja aí a chave para a compreensão da longevidade do "Jornal Pessoal".

"Contra o Poder" deixa bem claro que o jornal é de elite. "Não há outro destino para um jornal verdadeiramente independente, que rejeita publicidade desde o primeiro número" (Pinto, 2007, p. 9), explica o jornalista, que sentencia: "Com apenas 12 páginas, [...] sem cor, praticamente sem fotografia, escrito por um único redator, seu exemplar quinzenal custa três reais. É mais caro do que um jornal convencional. [...] $\bigcirc$ leitor enfrentará textos longos, analíticos, cheios de números e estatísticas, ironias, ceticismo e indignação" (Pinto, 2007, p. 9).

Talvez $\mathrm{O}$ alternativo pudesse atingir as classes mais populares se aceitasse publicidade. Entretanto, o jornalista

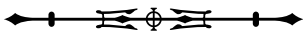


sabe que a entrada de anúncios nas páginas do "Jornal Pessoal" colocará em xeque a independência da proposta de mídia radical alternativa. Mas ele pondera: "se a sua difusão não pode ser ampla, o 'Jornal Pessoal' transforma essa limitação em arma de combate, pois seu grande objetivo é criticar a elite, fustigando-a, cobrando-lhe os compromissos devidos" (Pinto, 2007, p. 10).

O arcabouço teórico - munição de Lúcio Flávio Pinto contra a elite amazônica - é decorrente da partilha de idéias com intelectuais como Karl Manheim, Max Weber, Lucien Goldman, Wright Mills e Sigmund Freud (Pinto, 2007, p. 10). Se, por um lado, essa veia teórica citada pelo sociólogo não aparece de forma explícita em "Contra o Poder" no que tange ao rigoroso padrão científico-acadêmico, por outro, pode-se identificar que a luta do "Jornal Pessoal" se entrelaça nas fontes supracitadas. Wright Mills, por exemplo, autor de "A Elite do Poder", afirma: "Se tomarmos os cem homens mais poderosos da América, os cem mais ricos, os cem mais celebrados e os afastarmos das posições institucionais que hoje ocupam, dos recursos de homens, mulheres e dinheiro, dos veículos de comunicação de massa que hoje se voltam para eles - seriam então sem poder, pobres e não celebrados. Pois o poder não pertence a um homem. [...] Ser célebre, ser rico, ter poder, exige o acesso às principais instituições, pois as posições institucionais determinam em grande parte as oportunidades de ter e conservar essas experiências a que se atribui tanto valor" (Mills, 1968, p. 19).

Decerto, não é casual que a elite amazônica, de acordo com a análise de Lúcio Flávio Pinto, trava uma guerra intestina para a ocupação do poder nas instituições. Infelizmente, o fim último a ser perseguido não é a causa social. $\bigcirc$ leitor poderá conferir ao longo das 288 páginas que esta mesma elite, com seus mandos e desmandos, é apontada por ele como a principal responsável pela condição colonial da região em pleno século XXI.

No segundo e terceiro capítulos, o autor analisa as raízes do assassinato, em junho de 1987, do ex- deputado estadual pelo PMDB, Paulo Fonteles, advogado de posseiros no violento sul do Pará. E enfatiza que o alternativo só passou a existir porque o jornal "O Liberal", comprometido com empresários-anunciantes, não pôde publicar em suas páginas uma reportagem assinada por ele sobre a morte de Fonteles. O jornalista sustentava que os empresários Francisco Joaquim Fonseca, do Grupo JONASA, e Jair Bernardino de Souza, proprietário da empresa BELAUTO, haviam mentido em seus depoimentos à polícia, favorecendo o acobertamento dos autores intelectuais do assassinato, que conheciam (Pinto, 2007, p. 28). A reportagem foi parar no número inaugural do "Jornal Pessoal", com a impressão de graça saída da rotativa de "O Liberal".

O quarto capítulo diz respeito ao rombo de 30 milhões de dólares dado no Banco da Amazônia (BASA), em 1987, comandado por uma quadrilha que agia dentro desta instituição financeira, estando à frente o ex-diretor de Crédito Geral e presidente interino, Augusto Barreira Pereira, indicado para o cargo pelo então governador do Pará, Jader Barbalho, hoje deputado federal do PMDB (Pinto, 2007, p. 71).

É assunto também recuperado em "Contra o poder", no quinto capítulo, a nascente estrutura de comunicação de Jader Barbalho como parte vital de seu esquema de poder, começando com o jornal "Diário do Pará", em 1982, que o ajudou a ser eleito governador do Pará no ano seguinte; e a tumultuada trajetória empresarial do goiano Jair Bernardino, acusado por Lúcio Flávio Pinto de ser "testa-de-ferro" de Jader Barbalho na área da comunicação. Pelas mãos do empresário, as rádios Clube (AM), Carajás (FM) e a TV RBA passaram a compor o que o jornalista chama de império de comunicação do ex-governador do PMDB (Pinto, 2007, p. 77-78).

Esse capítulo ainda é composto por reportagens referentes às alianças que se formaram no estado entre partidos políticos e imprensa em períodos de campanhas eleitorais, bem como à luta declarada pelo monopólio da informação, deixando de lado todo e qualquer princípio

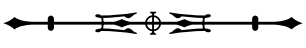


ético jornalístico. A análise de Lúcio Flávio Pinto recai no quadro político das eleições municipais da capital em 1988, envolvendo os veículos de comunicação de Jader e os da família Maiorana (Pinto, 2007, p. 102-114).

Em três longos capítulos, o sexto, sétimo e oitavo, o leitor terá de ser resistente para acompanhar o jornalista em suas análises políticas do governo conturbado de Jader Barbalho (1983-1987) e parte do de Hélio Gueiros (1988-1991), ambos marcados pela promiscuidade no trato da coisa pública.

Os exemplos são fartos, como as matérias referentes ao Banco do Estado do Pará (BANPARÁ), intitulado no livro como "O banco do Estado - e dos amigos" (Pinto, 2007, p. 132-137); ao Tribunal de Contas dos Municípios, caracterizado como "Um tribunal pessoal", criado sem obedecer ao critério constitucional de que cargo público só pode ser preenchido via concurso público (Pinto, 2007, p. 138-139); ao empreguismo sem paralelo no Pará, marcado pela entrada de quase 20 mil novos servidores no governo sem concurso público durante a primeira gestão de Jader, prática seguida pelo seu sucessor, Hélio Gueiros (Pinto, 2007, p. 183-208); ao poder paralelo dos banqueiros do jogo do bicho, uma contravenção penal em permanente relação de promiscuidade com o poder oficial (Pinto, 2007, p. 153-173); e ao tráfico de influência dos filhos de Gueiros, que se aproveitaram do poder do pai para fazer negócios e ganhar dinheiro por meio da empresa Estaleiros da Bacia Amazônica (EBAL), amparada pelo sistema de incentivos fiscais da Superintendência do Desenvolvimento da Amazônia (SUDAM) (Pinto, 2007, p. 174-178). Há, também, entre outros artigos, uma releitura crítica do prontuário do Serviço Nacional de Informação (SNI) contra Jader Barbalho, então ministro da Reforma e do Desenvolvimento Agrário no governo de José Sarney, em 1988, tendo como cerne da questão o rápido enriquecimento do político do PMDB (Pinto, 2007, p. 128-132).

Os capítulos finais são mais curtos e compõem matérias sobre a atuação dos grandes projetos de exploração de recursos naturais na Amazônia, que chegaram à região com a proposta de desenvolvê-la, mas que se revelaram estar baseados em um modelo econômico que associa elevadíssimos níveis de exploração de recursos naturais, grande volume de capital e um saldo perversamente negativo na área da responsabilidade social. Não obstante, são merecedores do aval de sucessivos governos, que isentam as empresas do pagamento de tributos. $\bigcirc$ resultado desta relação é o que 0 autor de "Contra o poder" chama de "Amazônia medieval".

Entre os exemplos, Lúcio Flávio Pinto cita a exploração da bauxita no vale do rio Trombetas, no município paraense de Oriximiná, pela empresa Mineração Rio do Norte (MRN), e os impactos sócio-ambientais causados pela implantação desse projeto. $\bigcirc$ jornalista narra o surto de gastrenterite que matou 12 pessoas em 1989, além de registros de doenças como leishmaniose, malária, hepatites, doença de chagas e esquistossomose, pois Oriximiná não contava com serviços básicos como água tratada e esgoto. Esses serviços só existiam em Porto Trombetas, o núcleo residencial dos funcionários da mineradora (Pinto, 2007, p. 224-229).

Outro tema da presente edição é Carajás, uma das mais importantes províncias minerais do planeta, em solo paraense, cuja exploração está por conta da Vale. Em reportagem datada de 1988, Lúcio Flávio Pinto já anunciava as sementes que levariam à privatização da empresa nove anos depois e dizia que o Pará não passava de mero acidente geográfico, pois não conseguia usufruir dos tesouros guardados nas entranhas da serra (Pinto, 2007, p. 236-242).

É destaque, ainda, as mortes de garimpeiros em Serra Pelada, no sul do Pará, em dezembro de 1987. O texto traz os bastidores da chamada "febre do ouro" no garimpo, criado por lei e mantido à custa do contribuinte brasileiro (Pinto, 2007, p. 243-266); além de análises referentes a um dos maiores índices de desmatamento na Amazônia, datado de 1987, em três estados: Pará, Rondônia e Mato Grosso. Juntos, queimaram 80 mil 
quilômetros quadrados de floresta nativa, sem qualquer relação com um processo produtivo em bases racionais (Pinto, 2007, p. 267-272).

Essa é a história narrada nas páginas do "Jornal Pessoal", muito longe da história oficial midiática da nossa contemporaneidade. Por isso, Lúcio Flávio Pinto convida a elite amazônica a "descer à rinha" para "ajustar o tempo da consciência ao da história" (Pinto, 2007, p. 10) na região impregnada no manto do colonialismo. Ademais, o livro - que encerra com 16 charges do artista gráfico Luiz Pinto, publicadas nas capas do periódico - é leitura obrigatória para a compreensão da história recente da Amazônia.
Em especial, para os que se interessam pela área da comunicação, pela força metajornalística que ensina os valores éticos de uma imprensa voltada para o cidadão.

\section{REFERÊNCIAS}

AMORIM, Célia Regina Trindade Chagas. Jornal Pessoal: Uma metalinguagem jornalística na Amazônia, 2008. 282 f. Tese (Doutorado em Comunicação e Semiótica) - Pontifícia Universidade Católica de São Paulo, São Paulo, 2008.

DOWNING, John. Mídia Radical: rebeldia nas comunicações e movimentos sociais. São Paulo: SENAC, 2002.

MILLS, C. Wright. A elite do poder. 2a . ed. Rio de Janeiro: Zahar Editores, 1968. 